\title{
COMPARISON BETWEEN RACEMIC BUPIVACAINE AND LEVOBUPIVACAINE; BOTH COMBINED WITH LOW DOSE FENTANYL, THROUGH INTRATHECAL ROUTE FOR TRANSURETHRAL RESECTION OF PROSTATE \\ Debalpana Chandra ${ }^{1}$, Subir Kumar Brahma ${ }^{2}$ \\ ${ }^{1}$ Senior Resident, Department of Anesthesiology, ESIC Medical College \& PGIMSR, Joka, Kolkata, India. \\ ${ }^{2}$ Resident Medical Officer (Anesthesiology), Malda Medical College, Malda, West Bengal, India.
}

\section{ABSTRACT}

Background and Objectives: Bupivacaine is available as a racemic mixture of dextro and levobupivacaine. Many studies show that dextrobupivacaine has greater cardiovascular and central nervous system toxicity than levobupivacaine. The objectives of the present study were to compare the effects of racemic Bupivacaine + Fentanyl and Levobupivacaine + Fentanyl on the complete regression of motor block, onset time to reach $\mathrm{T}_{10}$ level sensory block, duration of $\mathrm{T}_{10}$ level sensory block, onset time of motor block, duration of sensory block. Materials and Method: The study was conducted in 100 patients undergoing transurethral resection of prostate operation, who received either $1.75 \mathrm{ml}$ Bupivacaine $(0.5 \%)+25 \mu \mathrm{g}$ Fentanyl (Gr A) or $1.75 \mathrm{ml}$ Levobupivacaine $(0.5 \%)+25 \mu \mathrm{g}$ Fentanyl (Gr B) intrathecally. Results: Time to complete regression of motor block, onset time to $T_{10}$ level sensory block were significantly prolonged in $\mathrm{Gr}$ A compared to $\mathrm{Gr}$ B. The onset time of motor block was significantly shorter in $\mathrm{Gr}$ A compared to $\mathrm{Gr}$ B. There was no statistically significant difference between the two groups in respect to the duration of $T_{10}$ level sensory block, duration of sensory block. Conclusion: Intrathecal Levobupivacaine + Fentanyl used in the present study can be considered as a suitable alternative to Bupivacaine + Fentanyl for spinal anaesthesia in elective TURP surgery.

KEYWORDS: Isobaric; Racemic mixture; Intrathecal route; Transurethral resection.

\section{INTRODUCTION}

Transurethral resection of prostate (TURP), a urological operation remains the gold standard for treatment of benign prostatic hyperplasia (BPH). In TURP procedure a modified cystoscope (resectoscope) is passed up the urethra to the prostate where the surrounding tissues are excised using an electrically energized wire loop. Bleeding is controlled with coagulation current. Usually patients are elderly and suffer from cardiac, pulmonary, vascular and endocrine disorders [1]. TURP is also the surgical procedure of choice in men with symptomatic bladder outlet obstruction secondary to the bladder cancer or bladder neck contracture.

Neuraxial anaesthesia methods are preferred for transurethral procedures. Among the neuraxial anaesthesia, spinal anaesthesia or subarachnoid block is of choice. Spinal anaesthesia can be performed with local anaesthetics at different doses and baricity. [2]

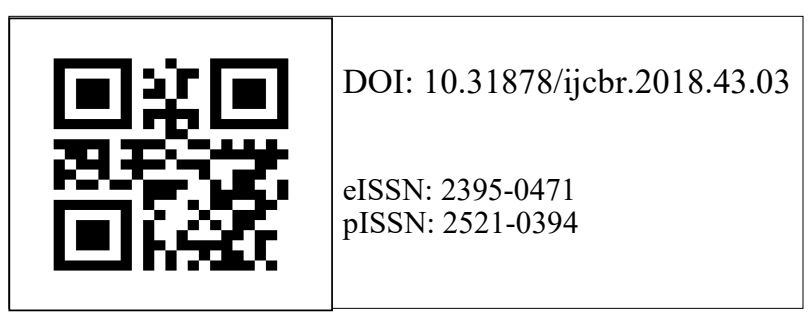

Spinal anaesthetic provides adequate anaesthesia for the patient and good relaxation of the pelvic floor and the perineum for the surgeon.

Local anaesthetics can be combined with opioids and this addition allows use of a lower dose of local anaesthetic, which results in more stable haemodynamics.

Bupivacaine is a racemic mixture of two enantiomers[Levorotatory (S-) and Dextrorotatory $(\mathrm{R}+)$ ]. It is a potent long acting amide linked local anaesthetic. It may prolong QTc interval and induce ventricular tachycardia or cardiac depression. [3]

Levobupivacaine hydrochloride is the pure $\mathrm{S}(-)$ enantiomer of racemic bupivacaine and is less toxic to the heart and central nervous system. [4,5]

The present study was designed to compare the effects of racemic Bupivacaine + Fentanyl and Levobupivacaine + Fentanyl on the complete regression of motor block, onset time to reach $\mathrm{T}_{10}$ level sensory block, duration of $\mathrm{T}_{10}$ level sensory block, onset time of motor block, duration of sensory block (regression time to $S_{1}$ dermatome level).

\section{MATERIALS AND METHODS}

Study design: Study was a randomized double blinded clinical trial.

Correspondence: Dr. Debalpana Chandra. Senior Resident, Department of Anesthesiology, ESIC Medical College \& PGIMSR, Joka, Kolkata. Email: ganga.chatterjee@gmail.com 
Debalpana et al. Comparison of racemic Bupivacaine \& Levobupivacaine, combined with low dose fentanyl for resection of prostate.

Ethical approval: This study was approved by institutional ethical committee (IEC). Informed consent was taken from each participant of this study.

Study location: R. G. Kar Medical College Hospital, Kolkata.

Study period: From December'2013 to November'2014

Inclusion criteria: This study was conducted in 100 ASA I-III male patients aged $50-80$ years undergoing Transurethral Resection of Prostate (TURP) operation at study place.

Exclusion criteria: Patients with serious CNS disorders, psychiatric disorders, decompensated cardiopulmonary disease, blood volume deficits, coagulopathy, peripheral neuropathies, infection at injection site, hypersensitivity to amide local anaesthetics and Fentanyl, unwilling patients were excluded from the study.

Randomization: The patients were randomly allocated of the clinical parameters for subarachnoid block characteristics $\&$ side effects of the drugs according to the study protocol was initiated.

Sensory blockade was assessed by pinprick test bilaterally along the midclavicular line. Motor blockade was assessed bilaterally in the lower limb according to modified Bromage Scale $(0=$ no motor block, $1=$ inability to raise extended legs, $2=$ inability to flex knees but able to move feet, $3=$ inability to flex ankle joints). Assessment of block was started after 5 minutes of the procedure and was repeated every 5 minutes for up to 6 hours postoperatively. The procedure was considered as failure when the onset of block did not appear within 15 minutes of the procedure. These patients were excluded from the study. Statistical analysis: Data of the study being non-Gaussian in distribution, MannWhitney $U$ test was applied to compare between different study groups.

RESULTS

Table 1. Distribution of Age, Body weight and comparison of Duration of operation in both the groups

\begin{tabular}{|l|l|l|l|l|l|}
\hline Variable & $\begin{array}{l}\text { Gr A } \\
\text { (Mean } \\
\text { Rank) }\end{array}$ & $\begin{array}{l}\text { Gr B } \\
\text { (Mean } \\
\text { Rank) }\end{array}$ & $\begin{array}{l}\text { Mann- } \\
\text { Whitney U }\end{array}$ & p value & Significance \\
\hline Age (Yrs) & 50.68 & 50.32 & 1241.000 & 0.950 & Not significant \\
\hline Body Weight (Kg) & 46.39 & 54.61 & 1044.500 & 0.155 & Not significant \\
\hline $\begin{array}{l}\text { Duration of } \\
\text { operation (Min) }\end{array}$ & 54.92 & 46.08 & 1039.000 & 0.119 & Not significant \\
\hline
\end{tabular}

in two groups. Lottery method was used for allocation of the study subjects randomly.

Grouping : Group A received $1.75 \mathrm{ml}$ Bupivacaine (0.5\%) + $25 \mu$ g Fentanyl (2.25 ml total drug volume) and Group B received $1.75 \mathrm{ml}$ Levobupivacaine $(0.5 \%)+25$ $\mu \mathrm{g}$ Fentanyl ( $2.25 \mathrm{ml}$ total volume) intrathecally. The patients were not pre-medicated.

Methodology: Heart rate (ECG), Non-invasive blood pressure (NIBP), Pulse oximetry $\left(\mathrm{SpO}_{2}\right)$, Respiratory rate (RR) were monitored in the operating room and baseline values were obtained before initiation of spinal anaesthesia.

An $18 \mathrm{G}$ intravenous cannula was inserted into peripheral vein preferably in the dorsal surface of patient's left hand. Normal saline was used as intravenous fluid in the intraoperative and postoperative periods. In both groups, patient positioning (sitting) was done and proper antiseptic measures (antiseptic dressing, draping) were taken. $26 \mathrm{G}$ Quincke type spinal needle was introduced at $\mathrm{L}_{2-3} / \mathrm{L}_{3-4}$ interspace in midline or paramedian approach. After return of clear CSF flow, study drug was administered within 30 seconds into subarachnoid space. After the spinal injection the patient was turned into supine position. Moist Oxygen @ 4 Lt/ min was given to the patient through face mask. The time of intrathecal injection was noted and monitoring
Patients in the two groups were comparable in terms of age, body weight, duration of operation, preoperative hemodynamic status (heart rate, mean arterial pressure).

We compared the spinal block characteristics using Mann-Whitney test and noticed that there was no significant difference in duration of $\mathrm{T}_{10}$ level sensory block and duration of sensory block between the two groups. Time to complete regression of motor block was significantly prolonged in $\mathrm{Gr}$ A compared to $\mathrm{Gr}$ B. Onset time to $T_{10}$ level sensory block was significantly prolonged in Gr A compared to Gr B. Onset time of motor block was significantly prolonged in Gr B compared to Gr A.

\section{DISCUSSION}

Levobupivacaine is increasingly popular in replacement of bupivacaine because of its equipotency with lower cardiovascular and central nervous system side effects. The lethal dose for levobupivacaine was significantly smaller than for bupivacaine.

In our study, two groups ( $A$ and $B$ ) were identical in respect to age, ASA physical status and body weight. There was no statistically significant difference between the two groups. Duration of operation was also comparable between the two groups. In this present study, time to complete regression of motor block 
Table 2. Comparison of Subarachnoid Block Characteristics in both the groups

\begin{tabular}{|l|l|l|l|l|l|}
\hline Variables & $\begin{array}{l}\text { Gr A } \\
\text { (Mean } \\
\text { Rank) }\end{array}$ & $\begin{array}{l}\text { Gr B } \\
\text { (Mean Rank) }\end{array}$ & $\begin{array}{l}\text { Mann- } \\
\text { Whitney U }\end{array}$ & p value & Significance \\
\hline $\begin{array}{l}\text { Time to complete } \\
\text { Regression of mo- } \\
\text { tor block in minutes }\end{array}$ & 59.70 & 41.30 & 790.000 & $0.001^{*}$ & Significant \\
\hline $\begin{array}{l}\text { Onset time to T } 10 \\
\text { level sensory block } \\
\text { in minutes }\end{array}$ & 68.09 & 32.94 & 372.000 & $0.000^{*}$ & Significant \\
\hline $\begin{array}{l}\text { Duration of } T_{10} \text { level } \\
\text { sensory block in } \\
\text { minutes }\end{array}$ & 52.74 & 48.26 & 1138.000 & 0.437 & Not significant \\
\hline $\begin{array}{l}\text { Onset time of motor } \\
\text { block in minutes }\end{array}$ & 46.00 & 55.00 & 1025.000 & $0.017^{*}$ & Significant \\
\hline $\begin{array}{l}\text { Duration of sensory } \\
\text { block in minutes }\end{array}$ & 55.72 & 45.28 & 989.000 & 0.070 & Not significant \\
\hline
\end{tabular}

(mins) was significantly prolonged in Gr A compared to Gr B. Similar result was found in the study done by $\mathrm{R}$. Hakan Erbay et al, [6] where they used $7.5 \mathrm{mg}$ hyperbaric Bupivacaine $+25 \mu \mathrm{g}$ Fentanyl in Gr B and $7.5 \mathrm{mg}$ hyperbaric Levobupivacaine $+25 \mu \mathrm{g}$ Fentanyl in $\mathrm{Gr} L$ in TURP surgery and found that the time to a Bromage score of zero (recovery of motor block) was shorter than in Gr B. Erkan Yavuz Akcaboy et al, [7] in a study used $5 \mathrm{mg}$ Levobupicaine $(0.5 \%)+25 \mu \mathrm{g}$ Fentanyl in one group and $5 \mathrm{mg}$ Bupivacaine $(0.5 \%)+25 \mu$ g Fentanyl intrathecally in another group in TURP surgery and found that time to complete regression of motor block was significantly shorter in first gr compared to second group. So, their finding was similar to our finding. Similar to our study was the finding of Gulen Gular et al.[8]

In our study, onset time to $T_{10}$ level sensory block (mins) was significantly prolonged in $\mathrm{Gr}$ A compared to Gr B. In the study done by F. Erdil et al, [9] the onset time to $T_{10}$ level sensory block was significantly shorter in Bupivacaine group than in Levobupivacaine group. The finding of Opas Vanna et al, [10] Lee et al, [11] was not similar to our finding.

In the present study, there was no statistically significant difference between the two groups in respect to the duration of $\mathrm{T}_{10}$ level sensory block.

Onset time of motor block ( $\mathrm{min}$ ) was significantly shorter in $\mathrm{Gr}$ A compared to $\mathrm{Gr}$ B. Our result corroborates with the finding of Demet Gulec et al, Gulen Guler et al, [8] Mantouvalou M. et al, who concluded that motor block onset time was significantly shorter in Bupivacaine gr compared to Levobupivacaine gr.

In the present study, there was no statistically significant difference between the two groups in respect to the duration of sensory block ( regression time to $S_{1}$ dermatome level) (mins). The finding of Opas Vanna et al, [10] Erkan Yavuz Akcaboy et al, Thepakorn Sathitkarnmanee et al, Luck JF et al, Thongrong $\mathrm{C}$ et al, was similar to our finding. In the study done by $\mathrm{R}$. Hakan Erbay et al, the time to full recovery of sensory block was shorter in Bupivacaine gr than in Levobupivacaine gr. So, the finding was not similar to our finding.

\section{CONCLUSION}

the results of the present study indicate that, The complete regression time for motor blockade, onset time to $\mathrm{T}_{10}$ dermatome level sensory blockade were significantly shorter in those patients receiving $1.75 \mathrm{ml}$ isobaric Levobupivacaine $+25 \mu \mathrm{g}$ Fentanyl intrathecally than those patients receiving $1.75 \mathrm{ml}$ hyperbaric Bupivacaine $+25 \mu$ g Fentanyl. The motor blockade onset time was significantly shorter in Bupivacaine gr compared to Levobupivacaine gr. There was no statistically significant difference between the two groups in respect to the duration of $\mathrm{T}_{10}$ level sensory block and regression time to $S_{1}$ dermatome level.

\section{REFERENCES}

1. Gravenstein D. Transurethral resection of the prostate (TURP) syndrome: a review of the pathophysiology and management. Anesth Analg. 1997;84:438-46.

2. Miller RD, Eriksson $\mathrm{LI}$ et al. Miller's anesthesia. $7^{\text {th }}$ ed. Philadelphia: Churchill Livingstone; 2010. Anesthesia and Renal and Genitourinary Systems. 211923.

3. Tripathy K.D. Essentials of Medical Pharmacology. 
Debalpana et al. Comparison of racemic Bupivacaine \& Levobupivacaine, combined with low dose fentanyl for resection of prostate.

5th edition. New Delhi: Jaypee Brothers; 2003.Local Anaesthetics. Page 326.

4. Glaser C, Marhofer P, Zimpfer G, Heinz MT, Sitzwohl C,Kapral S, Schindler I. Levobupivacaine versus racemic bupivacaine for spinal anesthesia. Anesth Analg 2002; 94: 194-8.

5. Cuvas O, Er AE, Ongen E, Basar H. Spinal anesthesia for transurethral resection operations: bupivacaine versus levobupivacaine. Minerva Anestesiol.2008;74:697-701.

6. Erbay Hakan R. et al. A comparison of spinal anesthesia with low-dose hyperbaric levobupivacaine and hyperbaric bupivacaine for transurethral surgery: a randomized controlled trial. Minerva Anestesiol. 2010;76:992-1001.

7. A. Y. Erkan et al. Low dose levobupivacaine $0.5 \%$ with fentanyl in spinal anaesthesia for transurethral resection of prostate surgery. JRMS. 2011;16(1):68-73.

8. Gulen Guler et al. Comparison of Spinal Anesthesia with Levobupivacaine and Hyperbaric Bupivacaine for Cesarean section: A Randomized Trial. OpenJournal Of Anesthesiology. 2012;2:84-9.

9. Erdil F. et al. The effects of intrathecal levobupivacaine and bupivacaine in the elderly. Anaesthesia Journal of the association of Anaesthetists of Great Britain and Ireland. 2009;64:942-6.

10. Vanna Opas et al. Levobupivacaine and Bupivacaine in Spinal Anesthesia for Transurethral Endoscopic Surgery. J Med Assoc Thai 2006;89(8):11339.

11. Lee YY et al. Levobupivacaine versus racemic bupivacaine in spinal anaesthesia for urological surgery. Anaesth Intensive Care. 2003;31;637-41.

How to Cite this article: Comparison between racemic bupivacaine and levobupivacaine; both combined with low dose fentanyl, through intrathecal route for transurethral resection of prostate. Int. j. clin. biomed. res. 2018;4(3): 10-13. 